\title{
MIXED RECYCLING WITH EMULSION AND CEMENT OF ASPHALT PAVEMENTS. DESIGN PROCEDURE AND IMPROVEMENTS ACHIEVED
}

\author{
R. Miró Recasens, F.E. Pérez Jiménez and S. Castillo Aguilar \\ Technical University of Catalonia, Spain
}

\begin{abstract}
Cold in place recycling, as an alternative to milling and standard replacement, shows a series of technical, economic and environmental advantages, which have done its use to grow in Spain, especially from 1990 onwards. Nevertheless, these actions have revealed certain aspects and limitations that prevent cold recycling from being considered a fully consolidated technique nowadays.

The use of vaguely defined criteria for the design of the recycled mix, the lack of criteria for construction control as well as of specifications about the end product, and the ignorance of the evolution of the material performance with time have given cold recycling some technical insecurity.

In this article, the problems arising from the standard methodology used for the design of cold recycled mixes have been analysed firstly, as well as the effect that certain variables, compaction and curing especially, have on their properties. Secondly, the effect that the use of both emulsion and cement during recycling has on the mix properties has been studied, comparing the results with those obtained by means of the standard procedures where only emulsion or cement are used. Finally, a new methodology for the design and control of the recycled mix has been suggested.
\end{abstract}




\section{RÉSUMÉ}

Le recyclage à froid en place comme alternative au fraisage et réposition conventionnel présente une suite d'avantages techniques, économiques et environnementaux, qui ont fait que leur utilisation en Espagne ait augmenté progressivement, surtout depuis 1990. Cependant, ces mêmes activités ont mis en évidence certains aspects et limitations qui empêchent le recyclage à froid d'être consideré, à présent, comme une technique de réhabilitation consolidée.

L'utilisation de critères de dessin de l'enrobé recyclé peu définis, la manque de critères de controle d'exécution ainsi que de spécifications sur le produit final, et la méconnaissance de l'évolution du comportement du matériel avec le temps, ont entouré le recyclage à froid d'une certaine insecurité technique.

Dans cet article on analyse, premièrement, les problèmes que pose la méthodologie que l'on utilise d'habitude dans le dessin des enrobés recyclés à froid et l'influence que certaines variables, compacité et endurciment spécialement, ont sur leur propriétés; en deuxième lieu, on a étudié l'effet sur les propriétés de l'enrobé de l'utilisation conjointe d'émulsion et ciment pendant le recyclage, que l'on a comparé avec celles obtenues lorsque l'on n'utilise que de l'émulsion ou que du ciment et, finalement, on a proposé une nouvelle méthodologie de dessin et controle de l'enrobé recyclé. 


\title{
MIXED RECYCLING WITH EMULSION AND CEMENT OF ASPHALT PAVEMENTS. DESIGN PROCEDURE AND IMPROVEMENTS ACHIEVED
}

\author{
R. Miró Recasens, F.E. Pérez Jiménez and S. Castillo Aguilar \\ Technical University of Catalonia, Spain
}

\section{INTRODUCTION}

The reuse of bituminous materials removed from aged pavements cannot be considered to be a new technique as far as maintenance and rehabilitation of pavements are concerned since its use, more or less widespread, began in 1973 as a consequence of the oil crisis. Cold in place recycling, as an alternative to milling and standard replacement, shows a series of well known technical, economic and environmental advantages: improvement of structural capacity and of pavement regularity, decrease in the use of aggregates and bitumen, lesser energy consumption, quick execution, waste disposal, does not cause smoke pollution, etc., while being a relatively inexpensive operation that provides a longer pavement service life, which is also environmentally friendly.

Encouraged by these advantages, the use of cold recycling in Spain has been gradually growing, especially from 1990 onwards, emulsion recycling being the most widely used, accounting for a $2.4 \times 10^{6} \mathrm{~m}^{2}$ of the recycled surface up to now, followed by cement recycling, with about $0.8 \times 10^{6} \mathrm{~m}^{2}$, Ruiz [1]. Nevertheless, these actions have revealed certain aspects and limitations that prevent cold recycling from being considered a fully developed and consolidated technique nowadays.

The use of vaguely defined criteria for the design of the recycled mix, the lack of criteria for construction control as well as of specifications about the end product, and the ignorance of the evolution of the material performance with time have given cold recycling some technical insecurity, causing road administrations to distrust the use of this technique. 
The aim of this article is to contribute to the clarification of some of these issues. It shows the results of a study about cold recycling of asphalt pavements, carried out at the Road Research Laboratory in the Transportation Department at the Technical University of Catalonia, following the monitoring of some of the actions undertaken in Catalonia (Spain).

From this starting point, the problems arising from the standard methodology used for the design of cold recycled mixes have been analysed firstly, as well as the effect that certain variables, compaction and curing especially, have on their properties. Secondly, the effect that the use of both emulsion and cement during recycling has on the mix properties has been studied, comparing the results with those obtained by means of the standard procedures where only emulsion or cement are used. Finally, a new methodology for the design and control of the recycled mix has been suggested, which is compatible with and complementary to the current methodology.

\section{ANALYSIS OF PROPORTIONING AND CONTROL PROCEDURES FOR THE RECYCLED MIX}

The standard procedure for the proportioning of the recycled mix is based on the Proctor test for determining the optimal compaction fluids content and in the standard test method for effect of water on compressive strength -immersion test- for the mechanic characterisation of the mix and the selection of emulsion content.

After characterising the milled material removed from the aged pavement (gradation of milled material and extracted aggregate, percentage and characteristics of the original bitumen), the optimal percentage of compaction humidity is determined, by means of the Modified Proctor compaction test. Then, a coating test is performed with an initial percentage of emulsion and water, the addition of both being equal to the Proctor humidity content. 
If the coating is good, specimens for the immersion test are produced -as appears in the Spanish norm NLT-162/84 [2]-, while increasing and decreasing the emulsion percentage in respect to the one initially fixed, but keeping the compaction fluids constant. After keeping the specimens in an oven at $60{ }^{\circ} \mathrm{C}$ for 72 hours, they are tested at simple compression determining the dry and after water immersion $\left(1\right.$ day at $\left.60^{\circ} \mathrm{C}\right)$ resistance.

The minimum emulsion percentage is established according to the simple compressive strength, which has to be over $1,500 \mathrm{~kg}$, and to the retained strength, equal or over $75 \%$, recommending not to have less than $2 \%$ by mass of residual binder even though the retained strength is over $75 \%$, because the possible homogeneity differences in milling during the road works could provoke superficial stripping in those areas with a higher quantity of fines. Although these criteria, backed up by experience, have been used there is no specification about them, but in the last years different values according to traffic category have appeared as well as requirements on the value of strength after immersion, Fernández del Campo [3].

However, this procedure poses several problems. The first and most important one is that the optimal emulsion percentage is selected on a more compact material than the one achieved during works. The real density obtained from cores, extracted within 30 and 60 days after the execution of several asphalt layers in place recycled with emulsion, is about $93 \%$ of the value obtained with the corresponding specimens produced in laboratory, using the static compaction of $17,000 \mathrm{~kg}$ standard specified.

Consequently, the properties of the mix produced in laboratory can be slightly different from the ones that the compacted mix will actually have. Fig. 1 shows the changes in compressive strengths of the recycled mix specimens in respect to the compaction energy used, noting that the most similar densities to the ones obtained during works $\left(2.27 \mathrm{~g} / \mathrm{cm}^{3}\right.$ on cores) are achieved with a $6,000 \mathrm{~kg}$ compaction load.

The second problem that this proportioning procedure poses is that compressive strength is evaluated for a pre-established period of time and curing conditions, ignoring the strength degree that will be achieved immediately after the execution -which is a very 
important value since the recycled mix layer is open to traffic once the compaction is over- as well as at the end of the maturation period, once the water excess coming from the emulsion breakage is suppressed. Figs. 2 and 3 reveal that the strengths obtained on specimens cured in ovens at $60{ }^{\circ} \mathrm{C}$ for 3 days are quite higher than those obtained at a very short term and fairly lower than the ones obtained at a longer term when specimens are cured at room temperature.

Thirdly, the immersion test is useful for revealing the effect of water on the mix, adhesiveness, but it is rather ineffective in order to characterise it mechanically. The test is by no means the most appropriate for determining the ductile and tough cohesion provided to the milling by the bituminous emulsion; an increase in the emulsion content usually brings about a decrease in compressive strength, Pérez Jiménez [4].

On the other hand, the technique of cold in place recycling has in itself an additional disadvantage: the difficulty of controlling the density during works.

The nuclear device usually controls the density during works, which should be aimed at being the highest possible. Nevertheless, with this procedure, the humidity measurement could not be accurate, given the fact that the bitumen existing in the old mix as well as the added one through the emulsion can be measured as water. Therefore, the recorded humidity is not real and could be about twice the real one. Consequently, the dry densities obtained through the nuclear device do not correspond to the real ones, being around 86 and 90\%, depending on the different cases, of the ones obtained from cores.

Besides, the densities measured in situ with the nuclear equipment evolve with time, as water coming from the emulsion breakage is lost, through evaporation or filtration, a more or less difficult process depending on weather conditions, thickness of the compacted layer and condition of the road base.

By way of illustration, Figs. 4 and 5 represent the evolution with time of average dry densities and humidities, measured in situ on road C-1410, together with those obtained from cores extracted out of the recycled layer. Therefore, the dry density obtained in situ varies 
from $1,860 \mathrm{~g} / \mathrm{cm}^{3}$, after the layer compaction is complete, to $1,942 \mathrm{~g} / \mathrm{cm}^{3}$ after 40 days, a value which is still distant from $2,119 \mathrm{~g} / \mathrm{cm}^{3}$ obtained on cores extracted between 1 or 2 months after its construction, or from $2,280 \mathrm{~g} / \mathrm{cm}^{3}$ corresponding to the job mix formula in this case.

The rest of parameters that are usually controlled during construction do not show so many problems. These parameters are: gradation of the milled material in order to check the milling process homogeneity, aggregate gradation after extraction and bitumen content to detect any variations in the existing mix in the aged pavement, and compressive strength, dry and after immersion, of the recycled mix in order to compare it with the one obtained in laboratory during the proportioning process.

In view of these considerations, improving the mechanical characteristics of the mix is considered, especially in the first moments after its construction, by the incorporation of both emulsion and cement in the recycling, adding new tests and production procedures that allow for a better correlation between laboratory results and work results.

This double treatment in place with both emulsion and cement for recycling asphalt pavement was used in 1992 by Sainton et al. [5, 6], with the purpose of simultaneously giving a higher rigidity to the typical solution of emulsion recycling and a higher flexibility to the treatment with cement, thus minimising the fissure processes of the latter. Engbers et al. [7] confirm this aspect and, moreover, reveal the good fatigue resistance of this mixed mix. Our study is mainly aimed at the analysis of the effect of this kind of treatment in the first stages of curing.

\section{ANALYSIS OF THE MIXED MIX PROPERTIES}

The experimental study has basically consisted in determining the properties, and their evolution with time, of the cold recycled mix using both emulsion and cement, comparing them with the ones obtained when only emulsion or cement is used. 
The compressive strength, the indirect tensile strength, and the dynamic moduli of five recycled mixes have been analysed: one with emulsion, two with cement and the other two with both emulsion and cement, made from the same milling material, removed from the asphalt pavement of road C-147, which was recycled with emulsion during the spring of 1996, Pérez Jiménez et al. [8] This material has been used with the same gradation employed during its construction in order to compare the laboratory results with those of the cores extracted.

Table 1 shows the proportioning of each mix. The percentages of water added to mixes $\mathrm{RE}, \mathrm{RC}-1$, and RC-2 are the required ones to obtain the optimal compaction fluids in the Modified Proctor test. The aim has been to maintain these optimal compacting fluids for remixed RM-1 and RM-2, modifying them slightly in order to obtain a similar water/cement ratio.

The specimens have been produced by static compaction, using a 6,000 $\mathrm{kg}$ load in order to obtain densities similar to those obtained during works. The curing of the specimens containing emulsion has been carried out at room temperature, whilst the ones containing only cement have been kept in a humid chamber for its curing.

\section{Simple compressive strength}

The evolution of the compressive strength of the mixed mix during the curing period, determined at $20{ }^{\circ} \mathrm{C}$ according to NLT-161/84 standard [9], is quite similar to that of the emulsion recycled mix, although the higher the cement addition is, the higher the strength values are, as shown in Fig. 6.

In the short term -seven days- the compressive strengths of the emulsion and cement formulations become quite similar to those of the cement formulations for whatever cement content, and after 28 days the effect of a higher or lower cement content starts to be 
perceptible. In the long run, from 60 days onwards, the cement recycled mixes are the ones showing higher strengths.

\section{Compressive dynamic modulus}

The compressive dynamic modulus, NLT-349/90 [10], has been determined at $20{ }^{\circ} \mathrm{C}$ and at a $10 \mathrm{~Hz}$ frequency.

The emulsion recycled mix shows the lowest dynamic moduli, and the lowest modulus increase during the curing period, going from 3,540 to $4,878 \mathrm{MPa}$ in a 7 to 90 day period, as seen in Fig. 7. The mixed mix reaches higher moduli, and the higher the cement percentage is, the higher its increase during the curing period will be. Therefore, a mix with $3.5 \%$ by mass of emulsion plus $2.5 \%$ by mass of cement goes from 4,071 to $6,006 \mathrm{MPa}$, and a mix with $3.5 \%$ by mass of emulsion plus $3.5 \%$ by mass of cement goes from 4,484 to $7,907 \mathrm{MPa}$ in the specified period.

The cement recycled mixes show the higher moduli; the higher the cement percentage is, the higher the moduli increase during the curing period will be.

\section{Resilient dynamic modulus}

The evolution of the instantaneous resilient modulus, at $20^{\circ} \mathrm{C}$ and $0.5 \mathrm{~Hz}$, NLT-360/91 [11], for the set of analysed formulations shows a tendency similar to the one previously obtained for the compressive dynamic modulus, but with lower values.

The emulsion recycled mix reaches the lowest values, the cement recycled mix the highest ones, and the mixed mix shows an intermediate performance. The higher the percentage of cement is, the higher the increase of the resilient modulus during the curing period for the cement formulations will be. 
In order to check the correlation degree between the curing conditions of the specimens in the laboratory and the ones that actually take place in the compacted layers, the instantaneous resilient moduli have been determined, at $20^{\circ} \mathrm{C}$ and $0.5 \mathrm{~Hz}$, on cores removed from road C-147 during the first 18 months after its construction, and which had been recycled with the same emulsion formulation used in the present study [8]. After 6 months, the modulus of cores of the recycled mix was 3,819 $\mathrm{MPa}$, reaching 5,620 $\mathrm{MPa}$ after 18 months. Fig. 8 reveals that the modulus obtained on cores after 6 months is reached within 45 days on specimens produced with the same density obtained during works, whilst more than 90 days are necessary to reach the values obtained after 18 months.

Simultaneously to the extraction of cores, some campaigns for measuring deflections with impact deflectometer were carried out, obtaining average moduli of 3,129 and 4,033 $\mathrm{MPa}$ after 6 and 18 months respectively for the set of asphalt layers -wearing course and recycled base-, which are slightly lower than the ones obtained on cores at $20{ }^{\circ} \mathrm{C}$, which also reveals the effect of the curing period.

\section{Indirect tensile strength}

The indirect tensile strength of the analysed mixes has been determined at $5{ }^{\circ} \mathrm{C}$, according to NLT-346/90 standard [12]. At this temperature, and in the short term -1 to 7 days-, the higher the cement contents are, the higher the strength of the mixed mixes is, while the cement mixes show the lowest strength, as seen in Fig. 9. However, the increase of strength in the mixed mixes is, in the long run, lower than the one obtained by emulsion or cement mixes. The final strength of the mixed mix remains between the strength obtained with the emulsion mix and the cement one.

The indirect tensile strength of the emulsion recycled mix, obtained on cores removed from road C-147 [8], has been 1,2 MPa after 6 months, and 1,4 MPa after 18 months. These results confirm the previously established correlation between the real curing conditions and the ones obtained in laboratory, since the value obtained on cores after 6 months is reached in 
specimens within 50 days, while after 90 days the specimens do not reach the value of the cores after 18 months.

\section{PROPOSED METHODOLOGY OF DESIGN}

As previously showed, the compression test presents some disadvantages which make it inaccurate for the characterisation and the proportioning of these mixes. The densities of the specimens are much higher than the ones obtained in situ, and the compressive strength decreases as the emulsion percentage increases. Besides, it is difficult to establish correlations between the compressive strength of these specimens and the one of the material used in place, since, given the thickness of the recycling, it is difficult to obtain cores that, once regularised, present the height needed for a compressive test. Therefore, it is impossible to determine the actual value of the compressive strength of the end product.

This is the reason why the possibility of using a different parameter for the design and control of the cold recycled mix is considered; this parameter should be more related to its performance and, therefore, it could be possible to determine by testing the cores removed from the constructed layer.

In view of the results previously showed, the use of the indirect tensile strength was considered, since the determination of this property presents a series of advantages: the elaboration of specimens is really fast since it needs less materials and it might always be determined on cores, and, therefore, the laboratory and in place results could be correlated.

The indirect tensile test, applied both statically and dynamically, as a design procedure for recycled mixes, was proposed by Kennedy et al. [13, 14], and it has been studied by several authors, Garrick and Biskur [15], and Bonvino [16]; some of whom have added some modifications in the reading system for the improvement of the test precision and repeatability, Adam [17], Roque and Buttlar [18], and Mohammad and Paul [19]. On the 
other hand, this test is being used as a quality control parameter in the construction of hot bituminous mixes, Pérez Jiménez [20].

Fig. 10 shows the indirect tensile strength at $5{ }^{\circ} \mathrm{C}$, dry and after water immersion (one day at $60{ }^{\circ} \mathrm{C}$ ), of specimens produced with different emulsion contents, keeping the compaction fluids constant, and using a $6,000 \mathrm{~kg}$ static compaction, for 1 to 3 days of curing in an oven at $60^{\circ} \mathrm{C}$. After 3 days of accelerated curing it is obtained, with $3 \%$ by mass of emulsion, the same strengths which are obtained on cores removed from the road after 18 months, which reveals that this procedure can reproduce the actual performance of this material, determining a property directly related to the cohesion of the mix.

On the evidence of the results obtained in the latest emulsion recycling works carried out in Catalonia, the minimum emulsion percentage to be used in the recycled mixes should achieve a $1.0 \mathrm{MPa}$ indirect tensile strength, at $5{ }^{\circ} \mathrm{C}$, determined on specimens statically compacted at $6,000 \mathrm{~kg}$ after 3 days of curing in an oven at $60{ }^{\circ} \mathrm{C}$, and a retained strength of $75 \%$ after water immersion, 1 day at $60{ }^{\circ} \mathrm{C}$.

\section{CONCLUSIONS}

The analysis of the methodology that is usually applied in Spain in the design and control of the cold recycled mixes has revealed some inconveniences, which should be resolved in order to obtain materials in the laboratories more similar to the ones obtained during works.

In that respect, the compaction load used in the production of specimens for recycled mix must be lower than the currently specified in order to obtain a material with a compaction level similar to the one obtained during works. In this sense, $6,000 \mathrm{~kg}$ seems to be an appropriate value. 
The compressive strength of the recycled mix does not seem to be the most convenient parameter in order to characterise its performance in the laboratory, since it does not value the cohesion of mix specifically, and it does not reveal the effect of the emulsion.

The indirect tensile strength seems to be the most appropriate property both for designing the mix and to control its subsequent construction, since allows us to evaluate the emulsion's effect in order to improve the cohesion of mix. The elaboration of specimens is really fast and it might always be determined on cores and, therefore, the laboratory and in place results could be correlated.

The use of a mixed mix, jointly recycled with emulsion and cement, allows improving the performance of the emulsion recycled mix, increasing both its compressive and resilient modulus, and without reaching the rigidity of the cement recycled mix. The improvement of its reaction to tension during the initial periods makes it especially appropriate to endure the traffic abrasive effect after its construction.

Therefore, the mixed mix shows better mechanical characteristics than the emulsion recycled mix, especially in the short term, when the mix has not yet acquired its maximum strength, and it will also be more flexible than the cement recycled mix, with less cracking and shrinkage disadvantages.

\section{REFERENCES}

[1] Ruiz, A., "Pavements recycling: final report and future actions. Technical and economics aspects", $4^{\text {th }}$ Pavements National Congress (only available in spanish). Segovia, June. 1998 13-38.

[2] NLT-162/84 "Standard test method for effect of water on compressive strength", NLT Standards (only available in spanish), (CEDEX, 1992).

[3] Fernández del Campo, J.A., "Stabilisation and recycling with emulsion", $4^{\text {th }}$ Pavements National Congress (only available in spanish). Segovia, June. 1998 59-65. 
[4] Pérez Jiménez, F.E., "Reference document for recycling: specification and standards. Current state and necessities", $4^{\text {th }}$ Pavements National Congress (only available in spanish). Segovia, June. 1998 73-76.

[5] Sainton, A., Bourdrel, D., "Procédé de double traitement à froid des matériaux au ciment et à l'émulsion de bitume", Revue Générale des Routes et des Aérodromes, 719 (1994) 34-41.

[6] Sainton, A., Serant, B., Maribas, J., Bourdrel, D., "Le retraitement de fraisats en place par le procédé Flexocim", Revue Générale des Routes et des Aérodromes, 720 (1994) $22-27$.

[7] Engbers, G., Smallegange, J.P., “The development of Emulscement ${ }^{\circledR}$ : a base material with a future", in "Reflective Cracking in Pavements", Proceedings of the Third International RILEM Conference. Maastrich, October. 1996 (E\&FN Spon) 18-29.

[8] Pérez Jiménez, F.E., Miró, R., Sánchez Caba, J., Páez, A. “Cold recycling with emulsion of road C-147 asphalt layers, Sort-Esterri d'Aneu section. Construction control and analysis", $4^{\text {th }}$ Pavements National Congress (only available in spanish). Segovia, June. 1998 247-257.

[9] NLT-161/84 "Simple compressive strength of bituminous mixes", NLT Standards (only available in spanish), (CEDEX, 1992).

[10] NLT-349/90 "Measurement of compressive dynamic modulus of highway materials", NLT Standards (only available in spanish), (CEDEX, 1992).

[11] NLT-360/91 "Resilient dynamic modulus of bituminous mixes", NLT Standards (only available in spanish), (CEDEX, 1992).

[12] NLT-346/90 "Indirect tensile strength of bituminous mixes", NLT Standards (only available in spanish), (CEDEX, 1992).

[13] Kennedy, T.W. "Characterisation of Asphalt Pavement Materials using the Indirect Tensile Test", Proceedings of the Association of Asphalt Paving Technologist, 46 (Asphalt Paving Technologist, San Antonio, 1977) 132-150.

[14] Kennedy, T.W., Perez, I. "Preliminary Mix Design Procedure for Recycled Asphalt Materials", Recycling of Bituminous Pavements, ASTM STP 662, (L.E. Wood, Ed., American Society for Testing and Materials, 1978) 47-67. 
[15] Garrick, N.W., Biskur, R.R. "Effects of Asphalt Properties on Indirect Tensile Strength". Transportation Research Record, 1269 (1990) 26-39.

[16] Bonvino, U. "Evaluation of the Cohesion of Bitumen Mixes by means of the Indirect Traction Resistance Test", in "Mechanical Tests for Bituminous Mixes", Proceedings of the Fourth International RILEM Symposium. Budapest, October. 1990 (Chapman and Hall) 85-104.

[17] Adam, J.F. "Evaluation of The Baladi Indirect Tensile Apparatus", Iowa Department of Transportation, 1990/01 (1990) 29.

[18] Roque, R., Buttlar, W.G. "The Development of a Measurement and Analysis System to accurately determine Asphalt Concrete Properties using the Indirect Tensile Mode", Journal of the Association of Asphalt Pavement Technologists, 1992.

[19] Mohammad, L.N., Paul, H.R. "Evaluation of Indirect Tensile Test for determining Structural Properties of Asphalt Mix”, Transportation Research Record, 1417 (1993) $58-63$.

[20] Pérez Jiménez, F.E. Use of indirect tensile test for quality control of bituminous mixes, Research report (only available in spanish), (Universitat Politècnica de Catalunya, 1998).

Table 1. Proportioning of each of the analysed mixes.

\begin{tabular}{|c|c|c|c|c|c|}
\hline \multirow{2}{*}{} & \multicolumn{5}{|c|}{ TYPE OF RECYCLED MIX } \\
\cline { 2 - 6 } & RE & RC-1 & RC-2 & RM-1 & RM-2 \\
\hline ECL-2 Emulsion (\% by mass) & 3.5 & & & 3.5 & 3.5 \\
\hline V-35 Cement (\% by mass) & & 5.0 & 7.0 & 2.5 & 3.5 \\
\hline Water (\% by mass) & 2.25 & 7.0 & 8.2 & 2.35 & 3.85 \\
\hline
\end{tabular}




\section{LIST OF TABLES AND FIGURES}

Table 1. Proportioning of each of the analysed mixes.

Figure 1. Variation of compressive strength of laboratory specimens with the compaction load.

Figure 2. Evolution of compressive strength of laboratory specimens with time and curing type. Compaction $6 \mathrm{t}$.

Figure 3. Evolution of compressive strength of laboratory specimens with time and curing type. Compaction $17 \mathrm{t}$.

Figure 4. Evolution of in situ and core densities with time.

Figure 5. Evolution of in situ humidities with time.

Figure 6. Evolution of the compressive strength of laboratory specimens of the analysed mixes.

Figure 7. Evolution of the compressive dynamic modulus, at $10 \mathrm{~Hz}$, of laboratory specimens.

Figure 8. Evolution of the instantaneous resilient modulus, at $0.5 \mathrm{~Hz}$, of laboratory specimens.

Figure 9. Evolution of the indirect tensile strength, at $5^{\circ} \mathrm{C}$, of laboratory specimens.

Figure 10. Variation of the indirect tensile strength at $5{ }^{\circ} \mathrm{C}$ with the used emulsion percentage. 


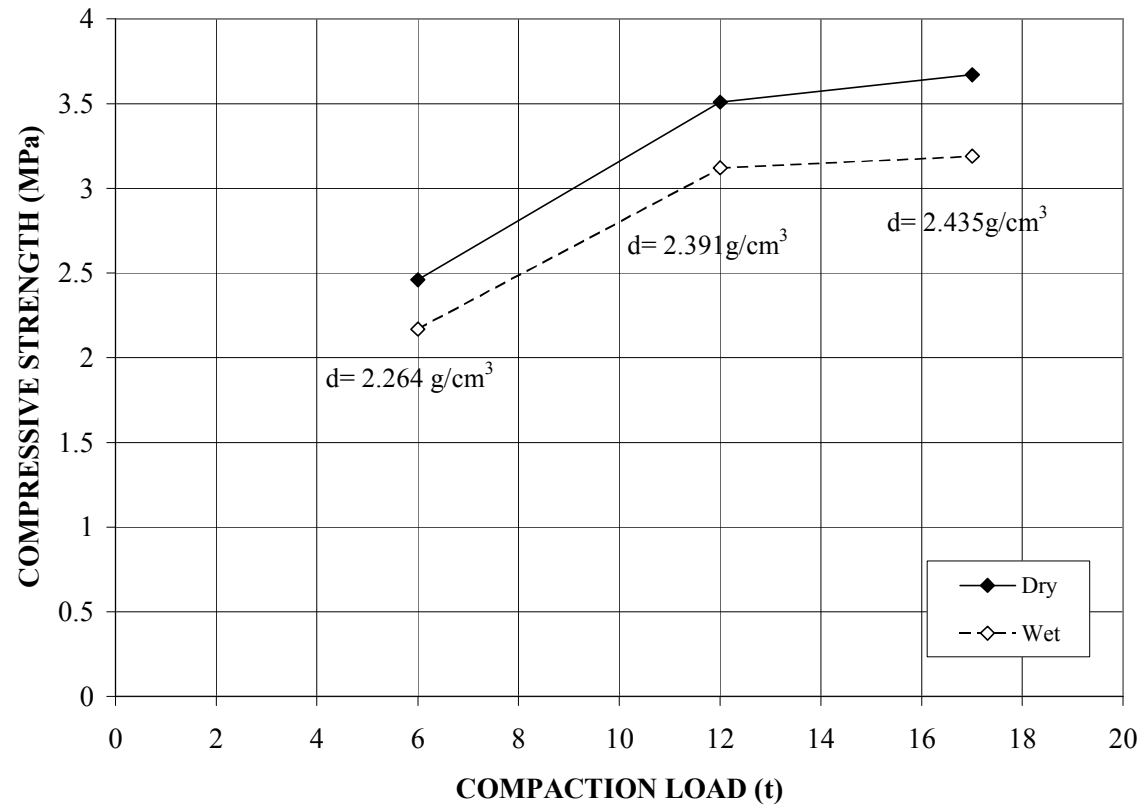

Figure 1. Variation of compressive strength of laboratory specimens with the compaction load.

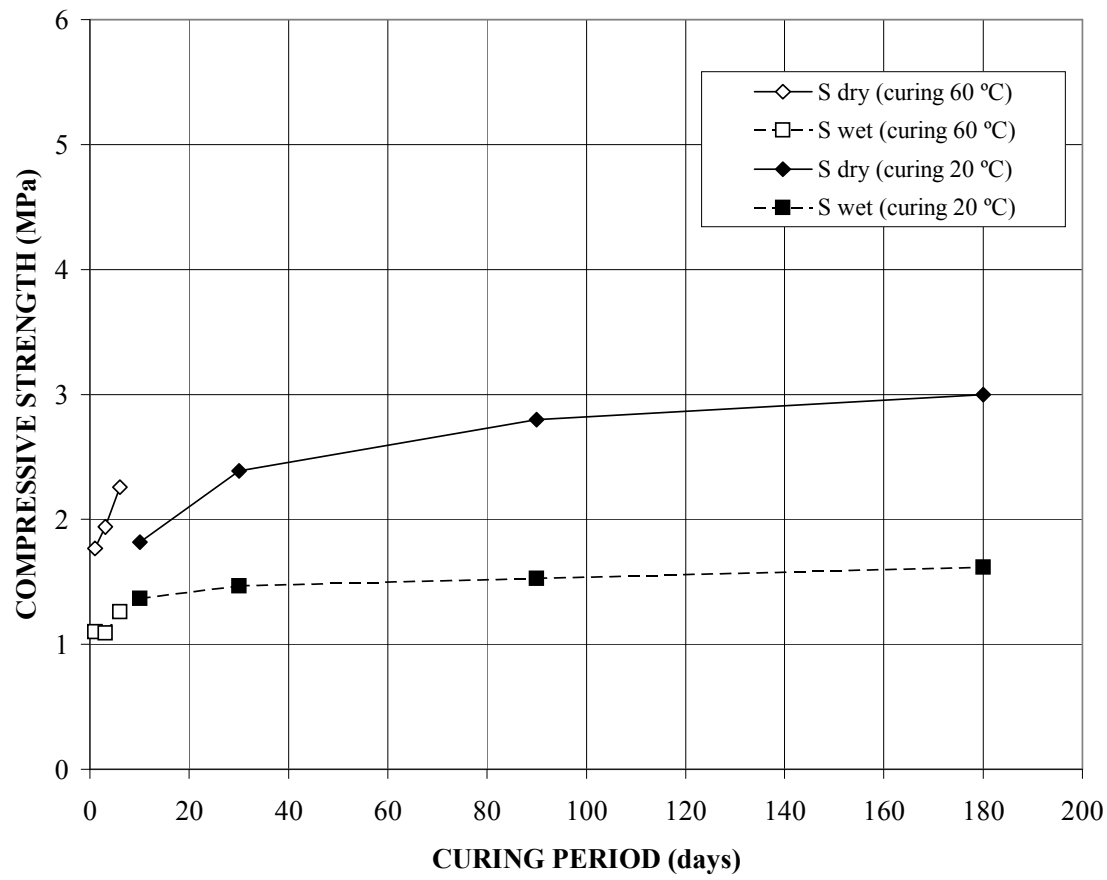

Figure 2. Evolution of compressive strength of laboratory specimens with time and curing type. Compaction $6 \mathrm{t}$. 


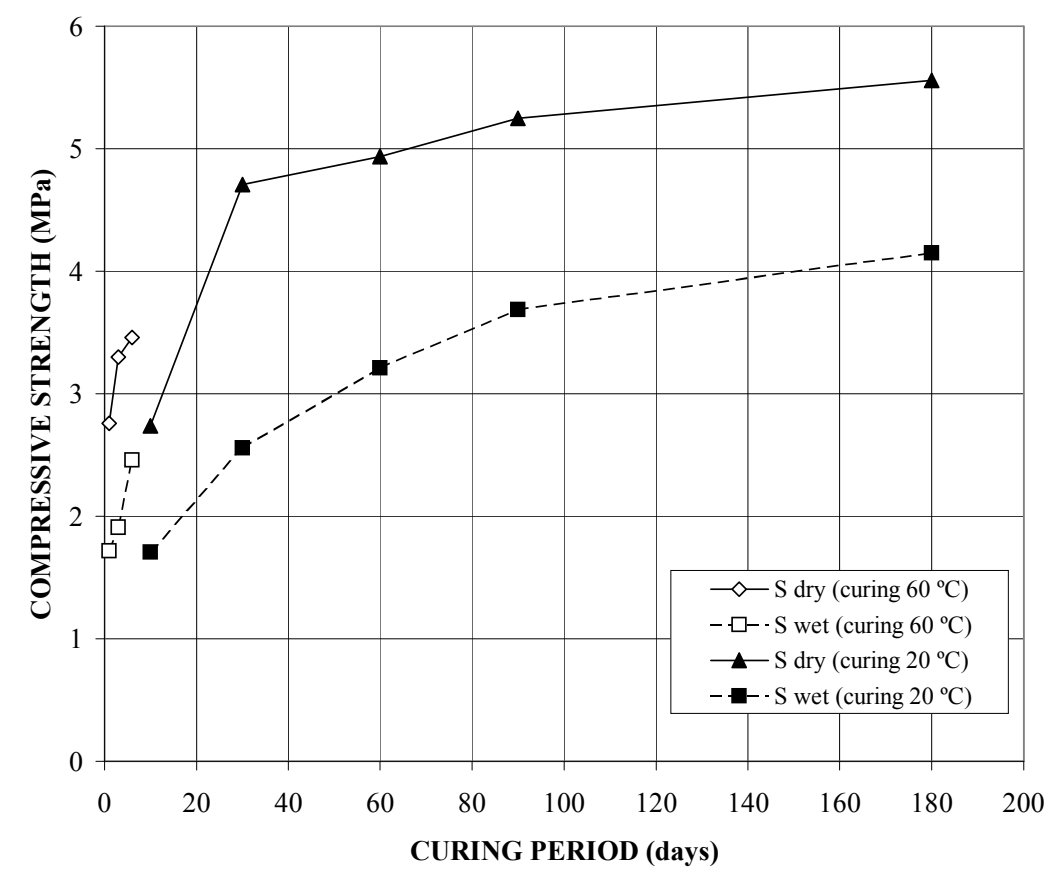

Figure 3. Evolution of compressive strength of laboratory specimens with time and curing type. Compaction $17 \mathrm{t}$.

COLD RECYCLING WITH EMULSION C-1410, section CARDONA-SOLSONA

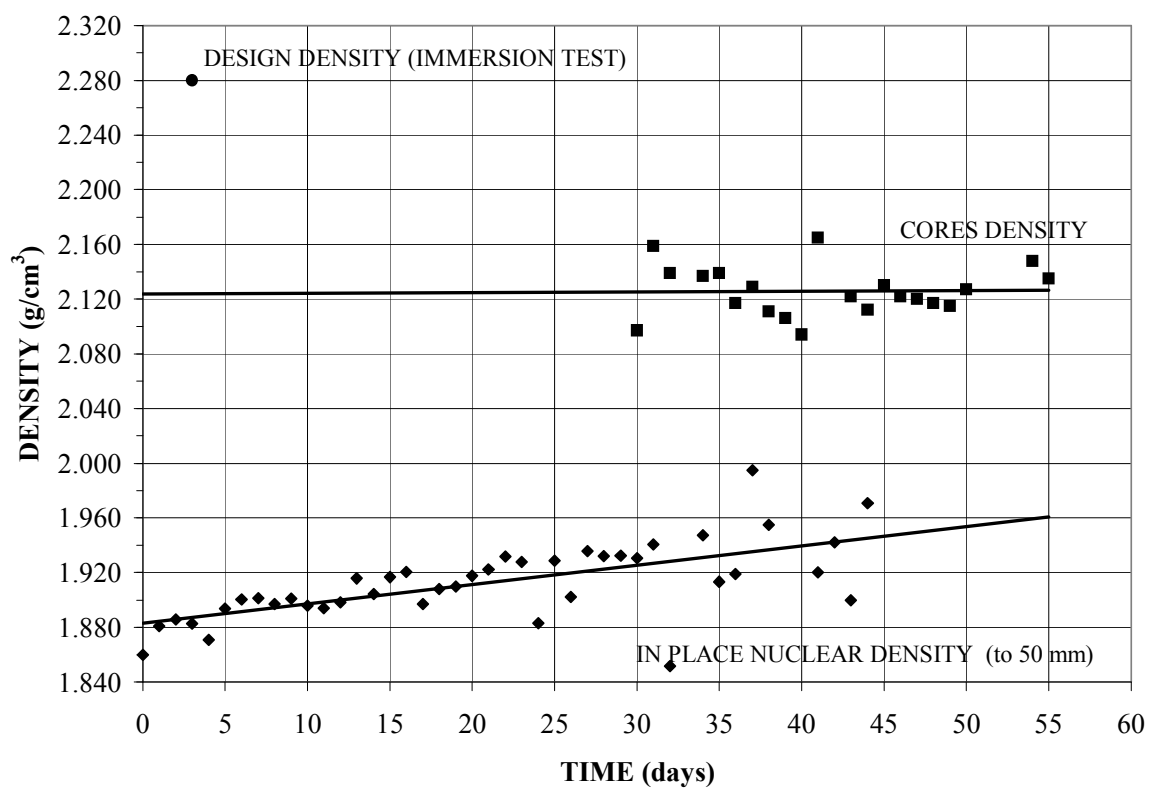

Figure 4. Evolution of in situ and core densities with time. 
COLD RECYCLING WITH EMULSION C-1410, section CARDONA-SOLSONA

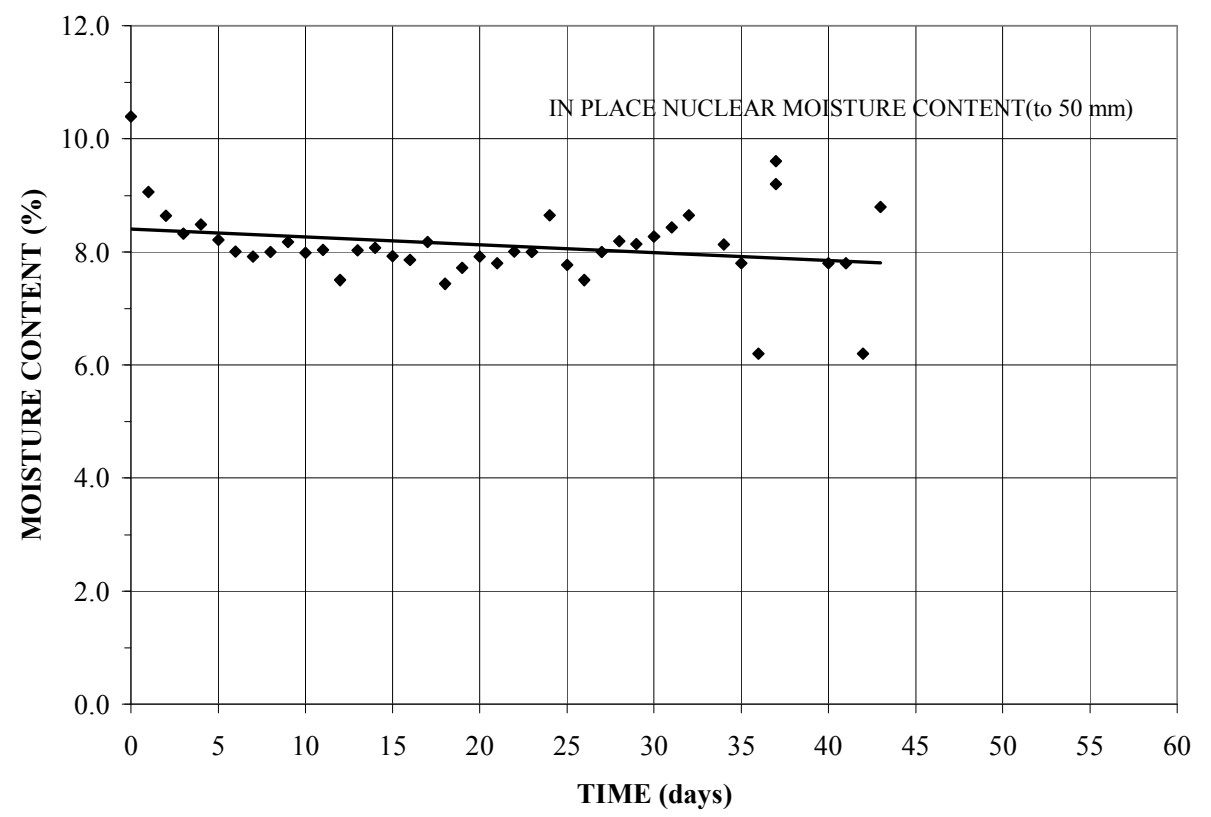

Figure 5. Evolution of in situ humidities with time.

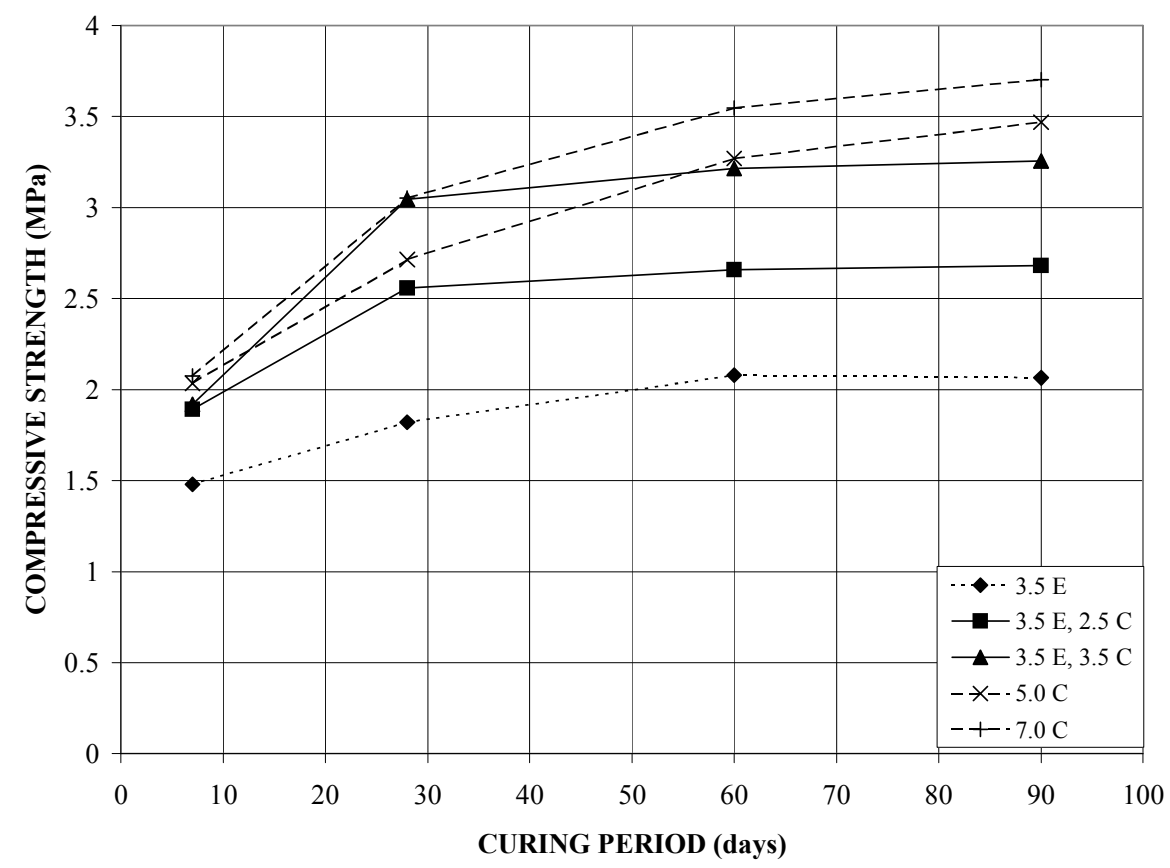

Figure 6. Evolution of the compressive strength of laboratory specimens of the analysed mixes. 


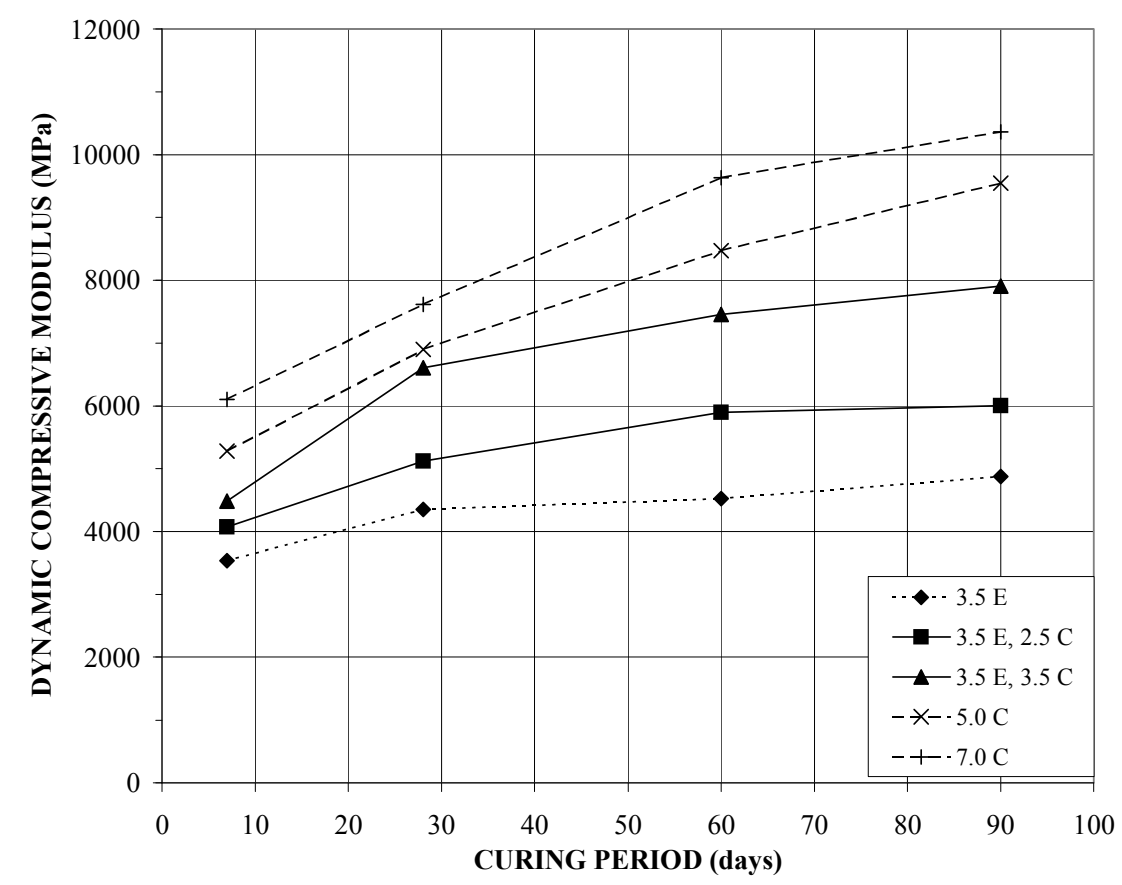

Figure 7. Evolution of the compressive dynamic modulus, at $10 \mathrm{~Hz}$, of laboratory specimens.

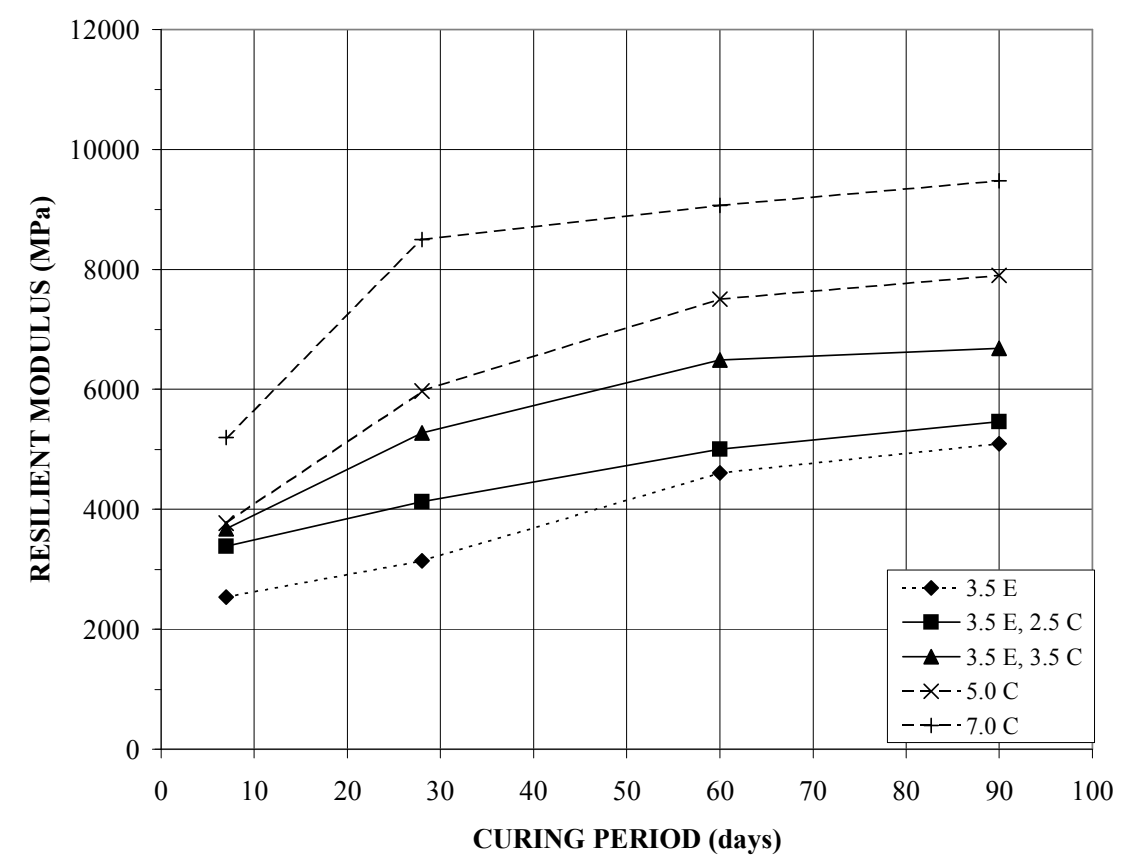

Figure 8. Evolution of the instantaneous resilient modulus, at $0.5 \mathrm{~Hz}$, of laboratory specimens. 


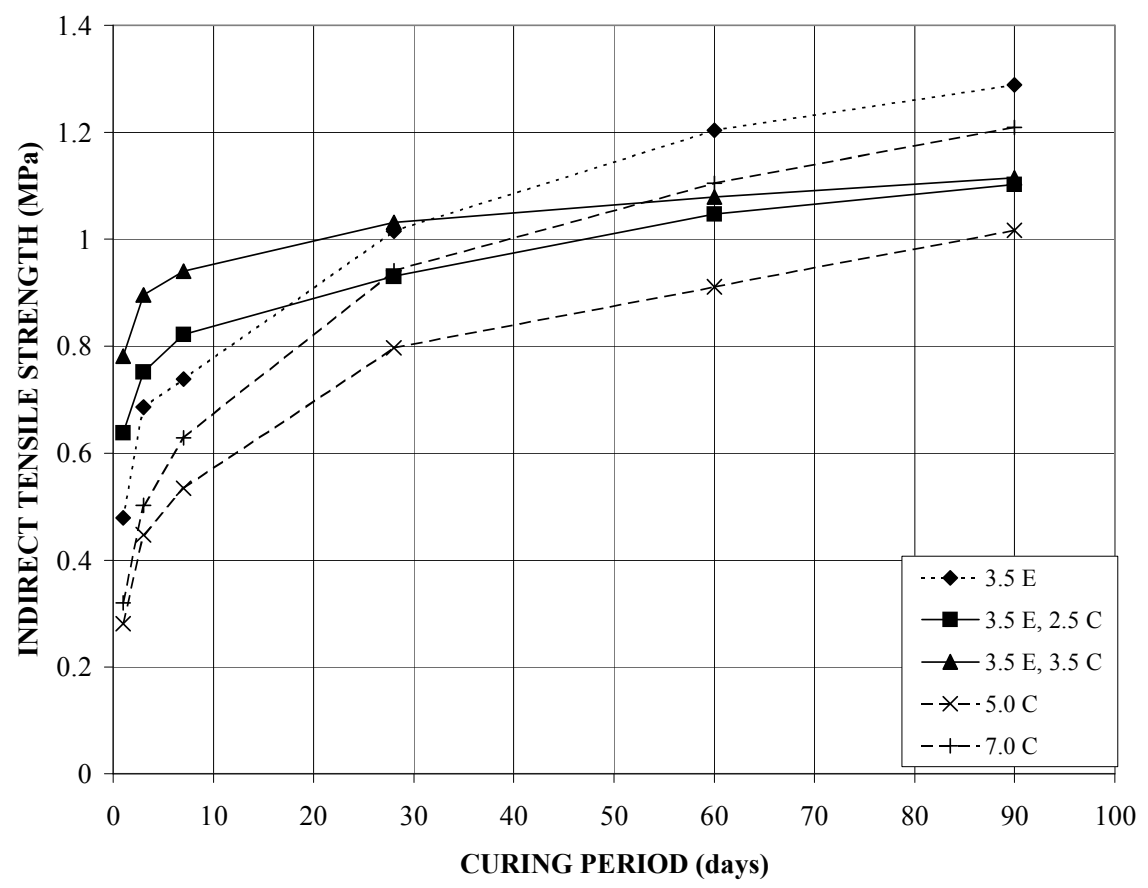

Figure 9. Evolution of the indirect tensile strength, at $5{ }^{\circ} \mathrm{C}$, of laboratory specimens.

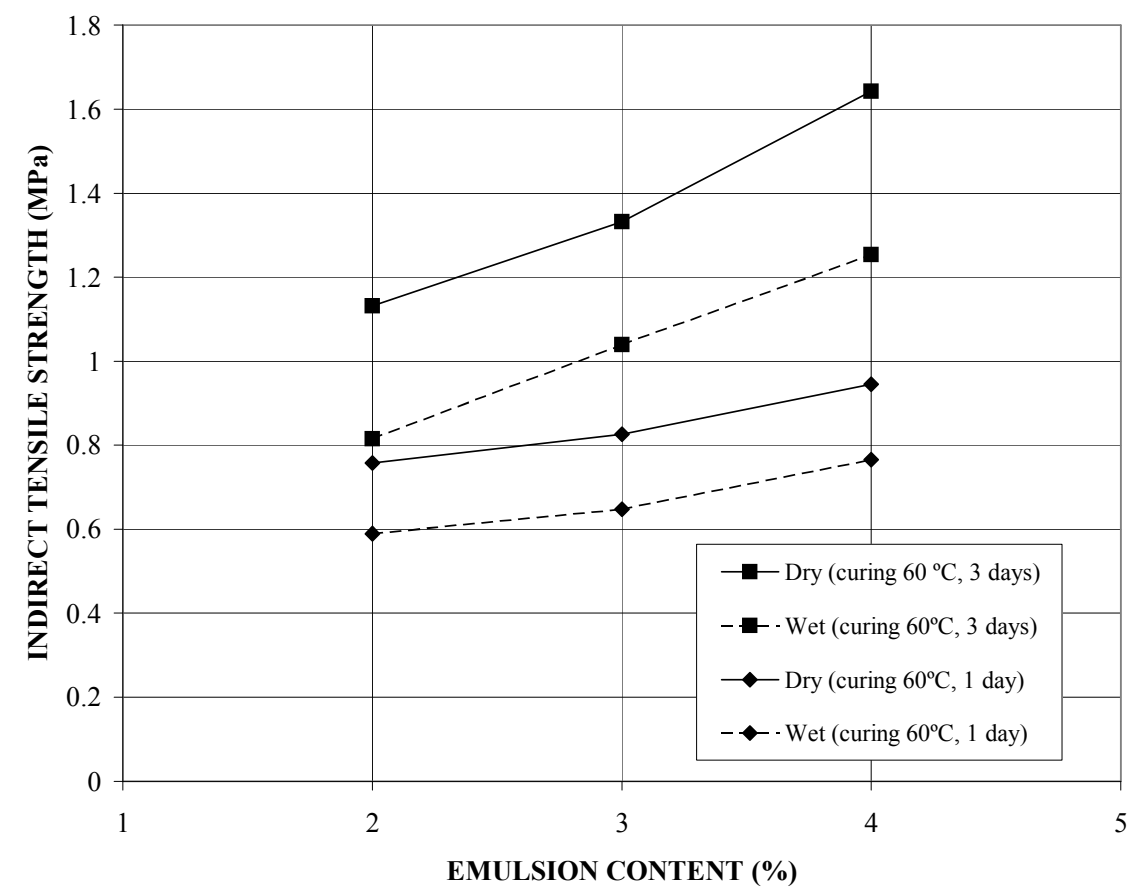

Figure 10. Variation of the indirect tensile strength at $5{ }^{\circ} \mathrm{C}$ with the used emulsion percentage. 